\title{
Rapid Estrogen Signaling in the Brain: Implications for the Fine-Tuning of Neuronal Circuitry
}

\author{
Deepak P. Srivastava, ${ }^{1,2}$ Elizabeth M. Waters, ${ }^{3}$ Paul G. Mermelstein, ${ }^{4}$ Enikö A. Kramár, ${ }^{5}$ Tracey J. Shors, ${ }^{6}$ and Feng Liu ${ }^{7}$ \\ ${ }^{1}$ Department of Physiology, Feinberg School of Medicine, Northwestern University, Chicago, Illinois 60611, ${ }^{2}$ Department of Neuroscience and Centre for the \\ Cellular Basis of Behaviour, The James Black Centre, King's College London, Institute of Psychiatry, London SE5 8AF, United Kingdom, ${ }^{3}$ Laboratory of \\ Neuroendocrinology, The Rockefeller University, New York, New York 10065, ${ }^{4}$ Department of Neuroscience, University of Minnesota, Minneapolis, \\ Minnesota 55455, ${ }^{5}$ Department of Psychiatry and Human Behavior, Irvine, California 92697, ${ }^{6}$ Department of Psychology and Center for Collaborative \\ Neuroscience, Rutgers University, Piscataway, New Jersey 08854, and 7Neuroscience Research Unit, Pfizer Global Research and Development, Groton, \\ Connecticut 06340
}

Rapid actions of estrogens were first described $>40$ years ago. However, the importance of rapid estrogen-mediated actions in the CNS is only now becoming apparent. Several lines of evidence demonstrate that rapid estrogen-mediated signaling elicits potent effects on molecular and cellular events, resulting in the "fine-tuning" of neuronal circuitry. At an ultrastructural level, the details of estrogen receptor localization and how these are regulated by the circulating hormone and age are now becoming evident. Furthermore, the mechanisms that allow membrane-associated estrogen receptors to couple with intracellular signaling pathways are also now being revealed. Elucidation of complex actions of rapid estrogen-mediated signaling on synaptic proteins, connectivity, and synaptic function in pyramidal neurons has demonstrated that this neurosteroid engages specific mechanisms in different areas of the brain. The regulation of synaptic properties most likely underlies the fine-tuning of neuronal circuitry. This in turn may influence how learned behaviors are encoded by different circuitry in male and female subjects. Importantly, as estrogens have been suggested as potential treatments of a number of disorders of the CNS, advancements in our understanding of rapid estrogen signaling in the brain will serve to aid in the development of potential novel estrogen-based treatments.

\section{Introduction}

The fine-tuning of neuronal circuits underlies the processing and storage of information in the brain. This fine-tuning, driven by changes in synaptic function and structure, is thought to be a key cellular determinant of memory and learning, behavior, and cognition (Chklovskii et al., 2004; DeBello, 2008; Holtmaat and Svoboda, 2009). Multiple factors, including genes, environment, and extracellular signals, contribute to the refinement of neuronal circuits. Critically, several pathologies of the brain, including stress, neurodevelopmental, neurodegenerative, and psychiatric disorders have been associated with abnormal neuronal circuitry (Fiala et al., 2002; van Spronsen and Hoogenraad, 2010; Penzes et al., 2011b). Moreover, it has been suggested that targeting the mechanisms that control the remodeling of neuronal circuitry may offer an avenue for the treatment of such disorders.

Estrogens have long been known to influence a number of physiological processes in the brain, including cognition and be-

Received Aug. 8, 2011; revised Sept. 26, 2011; accepted Sept. 27, 2011.

This work was supported by grants from the American Heart Association (0825719G) and National Alliance for Research on Schizophrenia and Depression (18087) to D.P.S.; NIH (AG039850 and AG167065) to E.M.W.; NIH (NS41302 and NS062158) to P.G.M.; NIH (NS045260 and NS051923) to E.A.K.; and NIH (MH-59970 and ARRAMH059970) and National Science Foundation (IOB-0444364 and IOS-0914386) to T.J.S. We thank Bruce McEwen, Peter Penzes, and Serena Dudek for thoughtful discussions on this Mini-Symposium, and Kelly A. Jones for editing of this manuscript.

Correspondence should be addressed to Deepak P. Srivastava or Feng Liu at the above addresses, E-mail: d-srivastava@northwestern.edu or Feng.Liu1@pfizer.com.

DOI:10.1523/JNEUROSCI.4097-11.2011

Copyright $\odot 2011$ the authors $\quad 0270-6474 / 11 / 3116056-08 \$ 15.00 / 0$ havior (McEwen and Alves, 1999; Luine, 2008; Brinton, 2009). The term "estrogens" refers to a class of biologically active C18 steroid hormones, of which estradiol is thought as the predominant biologically active form (Blaustein, 2008). Estrogens exert powerful effects on both molecular and cellular mechanisms, leading to the modulation of neuronal circuits, which ultimately is thought to contribute to this neurosteroid's effects on cognition and behavior. It is also important to note the difference between a neuroactive steroid and a neurosteroid (Paul and Purdy, 1992). Estrogens synthesized by an endocrine gland and secreted into the blood, where it can regulate target tissues such as the brain, are referred to as a neuroactive steroid. On the other hand, estrogens synthesized from androgen precursors, such as testosterone, or directly from cholesterol de novo in the brain are referred to as neurosteroids. Moreover, it is generally thought that the actions of neuroactive estrogens underlie the classic actions of this steroid, whereas that produced de novo in the brain may be the source of rapid estrogen signaling within the brain (Cornil et al., 2006).

Classically, estrogens' action has been described to occur via the regulation of gene transcription, taking hours to days to manifest (McEwen and Alves, 1999; Brinton, 2009). However, there is growing evidence that estrogens can rapidly influence cognition and behavior, as well as cellular and molecular events. Indeed, the emergence that brain-synthesized estrogens, mediated by the enzyme aromatase, may be the source of rapid estrogen effects within the brain (Balthazart and Ball, 2006; Garcia-Segura, 2008) 


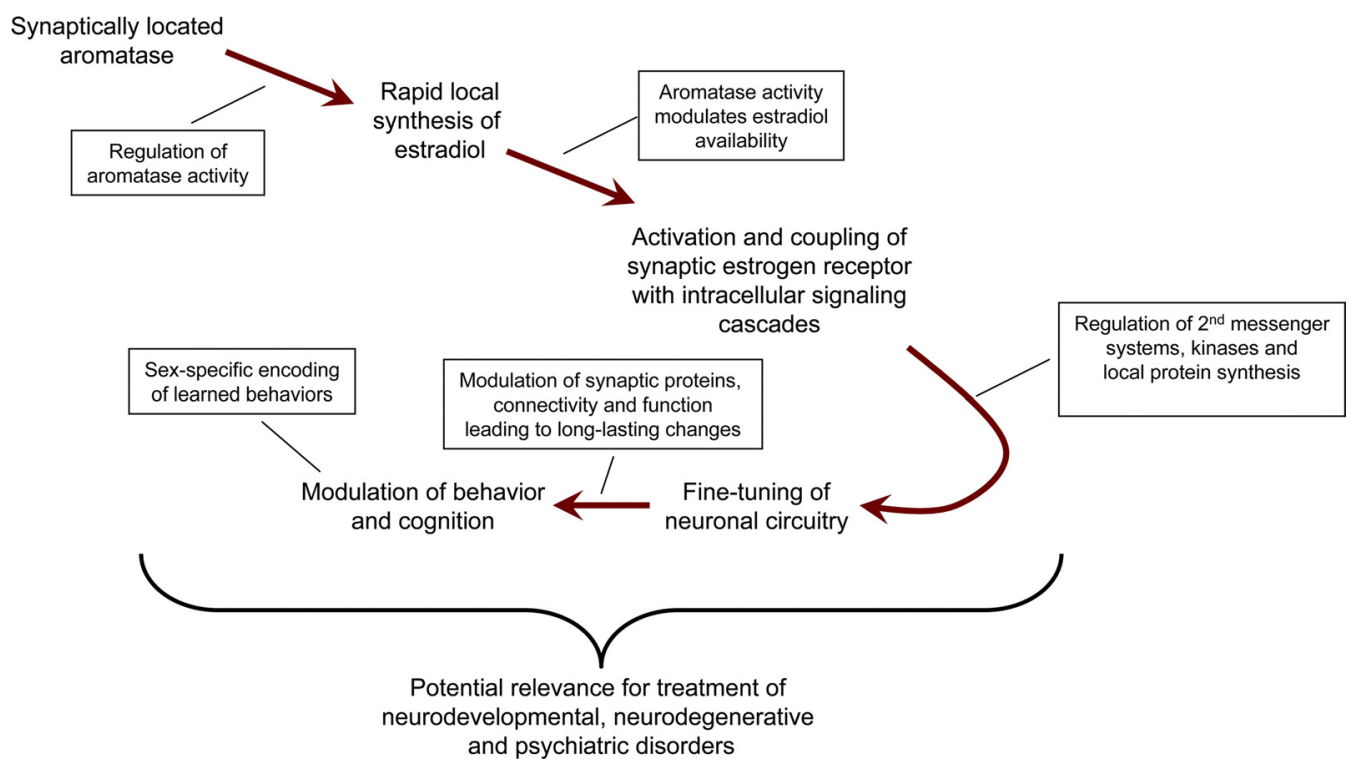

Figure 1. Emerging evidence suggests that rapidly synthesized estradiol within the brain, mediated by synaptically located aromatase, is the source of rapid estrogen signaling in the brain. Importantly, the regulation of aromatase will modulate the availability of estradiol within the brain. Exposure of estradiol results in the activation of synaptically localized ERs. The functional coupling of ERs with G-protein-sensitive mechanisms results in the initiation of second messenger systems and allows for the activation of multiple intracellular cascades, including those which converge onto the actin cytoskeleton and regulation of local proteins synthesis. This in turns leads to the modulation of synaptic proteins, connectivity, and function. Alterations in synaptic properties result in long-term changes in neuronal circuitry. Ultimately, these changes in neuronal circuitry contribute to rapid estradiol influences in behavior and cognition. Moreover, such mechanisms influence the circuitry used to encode learned behaviors in a sex-specific manner.

has galvanized research into detailing the consequence of rapid estrogen signaling on neuronal circuitry (Fig. 1). Furthermore, there is evidence that regulation of synaptically localized aromatase is a mechanism for the controlled production and release of estradiol from presynaptic terminals (Remage-Healey et al., 2011; Saldanha et al., 2011). This suggests that this neurosteroid may act as a neuromodulator, and is ideally placed to regulate the fine-tuning of neuronal circuits. Here we discuss recent advances in our understanding of rapid estrogen signaling, at multiple molecular and cellular levels, which broaden our overall comprehension of the mechanisms underlying estrogen-induced fine-tuning of neuronal circuitry (Fig. 1). First we will explore the synaptic localization of estrogen receptors and the mechanisms of how these receptors may couple their signals to second messenger pathways allowing for the generation of rapid cellular responses. We will then go on to describe how rapid estradiol signaling in either the cortex or hippocampus uses distinct molecular mechanisms to modulate synaptic structure and function. We will also describe how rapid estrogen signaling may influence sex differences in neuronal circuitry during the acquisition of learned behaviors under stressful conditions. Finally we will discuss the effect of estradiol on rapid protein synthesis through translation and the importance of this effect on synaptic structure and function. Altogether, the elucidation of the mechanisms underlying rapid modulation of neuronal circuits by estrogens may allow for a greater understanding of the potential for estrogen-based therapies for a range of neuropathologies (Fig. 1).

\section{Estrogen regulation of estrogen receptor $\alpha$ and $\beta$ suggests differential roles in neuronal plasticity}

There are two known forms of classical nuclear estrogen receptors (ERs), $\mathrm{ER} \alpha$ and $\mathrm{ER} \beta$. Both $\mathrm{ER} \alpha$ and $\mathrm{ER} \beta$ are found in nuclear and extranuclear sites throughout the brain. In the hippocampus, electron microscopic studies have revealed that ER $\alpha$ and $\operatorname{ER} \beta$ immunoreactivity are located predominantly at extranuclear sites, including dendritic spines, axons, terminals, and glia (Milner et al., 2001, 2005; Mitterling et al., 2010). The localization of ERs throughout cell compartments, coupled with the multiple cellular sites of actions of estrogen in addition to inputs originating from other estrogen-sensitive brain regions, serves to highlight the complex modulatory effects of estrogen mediated by ERs. The general lack of nuclear ERs, even during highestrogen states, is highly suggestive of an environment in which ERs, rather than translocating into the nucleus to alter cellular physiology through gene transcription, act locally to modulate cell signaling pathways that have immediate or rapid effects on cell behavior. Through these rapid effects on cell signaling pathways, activation of ERs outside the soma can lead to gene transcriptional effects although on a longer timescale. However, the extracellular localization of these ERs provides compelling evidence that estrogens' rapid effects on synapses occur locally rather than through regulation of nuclear transcription.

In the hippocampal formation, extranuclear $\operatorname{ER} \alpha$ is found in pyramidal and granule cells, while nuclear ER $\alpha$ immunoreactivity is found only in interneurons (Milner et al., 2001, 2005). In the postsynaptic cell, ER $\alpha$ immunoreactivity is found in dendritic spines, many originating from pyramidal cells, in association with spine apparatuses and/or polyribosomes. In presynaptic structures, ER $\alpha$-labeled unmyelinated axons and axon terminals containing synaptic vesicles form asymmetric and symmetric synapses, suggesting that $\mathrm{ER} \alpha$ may be expressed in cells other than interneurons. In the CA1 stratum radiatum, some of the $\mathrm{ER} \alpha$-labeled terminals are cholinergic, originating in the medial septum/diagonal band (Towart et al., 2003). ER $\alpha$ is also present in astrocytes that are often found near the spines of pyramidal cells (Milner et al., 2005) and microglia (Sierra et al., 2008). Interestingly, $\mathrm{ER} \alpha$ immunoreactivity varies across the estrous cycle, and labeling is highest in metestrus females (low, rising estrogen levels), particularly in dendritic spines, axons, and glia compared to proestrous and estrous females and males.

On the other hand, $\mathrm{ER} \beta$ immunoreactivity is often detected on or near the plasma membrane of somata and dendritic shafts 
and spines in hippocampal neurons (Milner et al., 2005). Furthermore, ER $\beta$ has been localized in axons and axon terminals and both in the cytoplasm and on endomembranes near mitochondria in vivo (Milner et al., 2005) and within mitochondria in vitro (Yang et al., 2004). ER $\beta$ immunoreactivity is present primarily in pyramidal cells but also is found in newly generated cells in a few interneurons and in glia (Milner et al., 2005; Herrick et al., 2006). The amount and types of ER $\beta$-labeled profiles has been shown to vary depending on sex and estrous cycle phase (Mitterling et al., 2010). In particular, ER $\beta$-labeled dendritic spines and glial profiles were more numerous in estrous and diestrous females (low-estrogen phases) compared to proestrous females and males.

More recently, synaptic ERs have been shown to be regulated by estrogen in an age-dependent manner. In the hippocampal region CA1 stratum radiatum, estradiol treatment increases synaptic ER $\beta$ labeling both in young and aged female rats compared to vehicle-treated animals (Waters et al., 2011). Conversely, synaptic $\mathrm{ER} \alpha$ immunoreactivity is decreased by estradiol in young animals and unaffected by estrogen in aged animals (Adams et al., 2002). These selective effects of estradiol on ER expression have been shown to occur within targeted areas of the synapse. Changes in ER $\beta$ expression occur in the presynaptic membrane, cleft, and postsynaptic membranes, where neurotransmitter release and postsynaptic receptor binding occurs. Conversely, ER $\alpha$ changes are detected presynaptically in synaptic vesicles and postsynaptically in plasmalemmal and cytoplasmic regions of spine heads where protein translation occurs. Accordingly, alterations in the ratio of $\operatorname{ER} \beta$ to $\operatorname{ER} \alpha$ likely contribute to changes in estrogen-modulated synaptic function and behavior across the lifespan, including age-related decline of estrogen-induced synapse formation (Adams et al., 2001) and hippocampal-dependent memory (Boulware et al., 2011).

\section{Estrogen receptor interactions with mGluRs}

The evidence that ERs are found at extranuclear sites in a number of cell types, including neurons, suggests that these receptors may be able to couple to traditional second messenger signaling pathways. While the membrane actions of estrogens (and other steroid hormones) impact a variety of cells and cellular functions, the identity (and even existence) of the cognate membrane receptors has for years remained controversial (Micevych and Mermelstein, 2008). This controversy has subsided in recent years, as in most cell types, membrane-initiated steroid hormone action appears due to the activation of a subpopulation of classical nuclear receptors that have been modified to traffic to and act at the surface membrane (Levin, 2011). Clues to the mechanism by which membrane-localized $\operatorname{ER} \alpha$ and $\operatorname{ER} \beta$ exert effects on cell function came from descriptions that estrogen's actions are sensitive to G-protein manipulation (Mermelstein et al., 1996; Qiu et al., 2003). Subsequent studies have determined that membranelocalized $\operatorname{ER} \alpha$ and $\operatorname{ER} \beta$ are capable of activating multiple metabotropic glutamate receptors (mGluRs) independent of glutamate, leading to downstream second messenger signaling (Boulware et al., 2005; Grove-Strawser et al., 2010).

First described in female hippocampal neurons, estradiol stimulation of membrane $\mathrm{ER} \alpha$ was found to trigger mGlula signaling. This led to the activation of $\mathrm{G}_{\mathrm{q}}$-mediated stimulation of phospholipase C (PLC), protein kinase C (PKC), and inositol trisphosphate (IP3) signaling, and eventual MAPK-dependent CREB phosphorylation. In the same population of neurons, membrane-localized $\mathrm{ER} \alpha$ and $\mathrm{ER} \beta$ could also trigger activation of mGlu2, leading to $\mathrm{G}_{\mathrm{i} / \mathrm{o}}$-coupled decreases in cAMP and subse- quent attenuation of L-type calcium channel-dependent CREB phosphorylation. While CREB phosphorylation is only one of many downstream targets of mGluR signaling, it was somewhat odd to observe these opposing processes working within the same cell. A follow-up study then established that there was spatial segregation of these two opponent processes through expression of multiple caveolin proteins (Boulware et al., 2007). Specifically, caveolin-1 expression is essential for the functional coupling and compartmentalization of ER $\alpha$ with mGlula. In contrast, isolation of $\operatorname{ER} \alpha$ and $\operatorname{ER} \beta$ with mGlu2 is achieved via expression of caveolin-3. Taken with the recent evidence of de novo estradiol synthesis within the hippocampus and other brain regions (Woolley, 2007), it seems highly likely that activity-dependent estradiol signaling can play an essential role in the modulation of discrete signaling units within individual cells, affording finetuned control of neuronal excitability.

Recent studies have examined potential $\mathrm{ER} / \mathrm{mGluR}$ interactions in other brain regions. Analogous to results from studies in hippocampal tissue, activation of $\mathrm{ER} \alpha$ leads to the phosphorylation of CREB, whereas ER $\alpha$ and ER $\beta$ attenuate L-type calcium channeldependent CREB phosphorylation in female striatal neurons (Grove-Strawser et al., 2010). Both pathways were similarly dependent upon CAV1 and CAV3. However, surprisingly the mGluRs responsible for membrane estrogen receptor signaling in striatum are different. In substitution of mGlula, ER $\alpha$ is functionally coupled to mGlu5. Likewise in striatum, $\mathrm{ER} \alpha$ and $\mathrm{ER} \beta$ are paired with mGlu3 (as opposed to mGlu2). These results are particularly intriguing as all four mGluRs are expressed in both hippocampus and striatum. Regardless of the mechanism for differential pairing of ERs and mGluRs across neuronal subtypes, these data suggest that ERs may be coupled to various GPCRs, and not a select population.

In rapid succession, the functional coupling of estrogen receptors to mGluRs has been demonstrated within many other regions of the nervous system. As examples, in the arcuate nucleus, $\mathrm{ER} \alpha / \mathrm{mGlu}$ la signaling impacts lordosis (Dewing et al., 2007). Within hypothalamic astrocytes, $\mathrm{ER} \alpha$ activation of mGlu1 is essential for neuroprogesterone synthesis and regulation of the estrous cycle (Kuo et al., 2010; Micevych et al., 2010). In dorsal root ganglion (DRG) neurons, estrogen receptor activation of mGlu2/3 attenuates ATP-induced increases in intracellular calcium (Chaban et al., 2007). Additionally, estrogen-induced masculinization of the medial preoptic area is dependent upon mGluR activation (Wright and McCarthy, 2009). It would be expected that these may be just some of the many examples of $\mathrm{ER} / \mathrm{mGluR}$ coupling that occur within the nervous system.

\section{Modulation of cortical neuron connectivity: a role for estrogen-induced "two-step wiring plasticity"}

In addition to the work described above, recent studies have started to uncover the complex effects of rapid estrogen signaling at the cellular level. In pyramidal neurons, dendritic spines form the postsynaptic compartment of synapses and are the site for the majority of excitatory synapses in the mammalian forebrain (Alvarez and Sabatini, 2007; Penzes et al., 2011a). These structures are rich in actin and readily undergo changes in morphology (size and/or number) in response to a number of stimuli (Alvarez and Sabatini, 2007; Kasai et al., 2010a). Moreover, changes in dendritic spine morphology are often accompanied by alterations in synapse function, and thus mediate the remodeling of neuronal circuitry (Segal, 2005). Therefore, understanding the actions of estrogens on dendritic spine structure and function may offer an insight into the means by which this neurosteroid may rapidly modulate neuronal circuitry. 
a

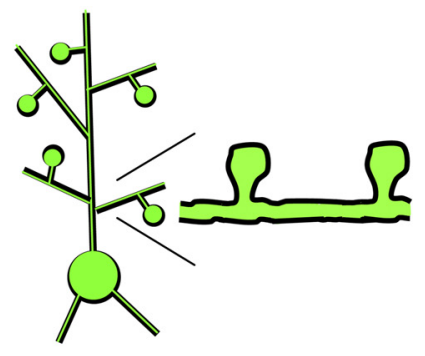

Cortical neuron

b

C
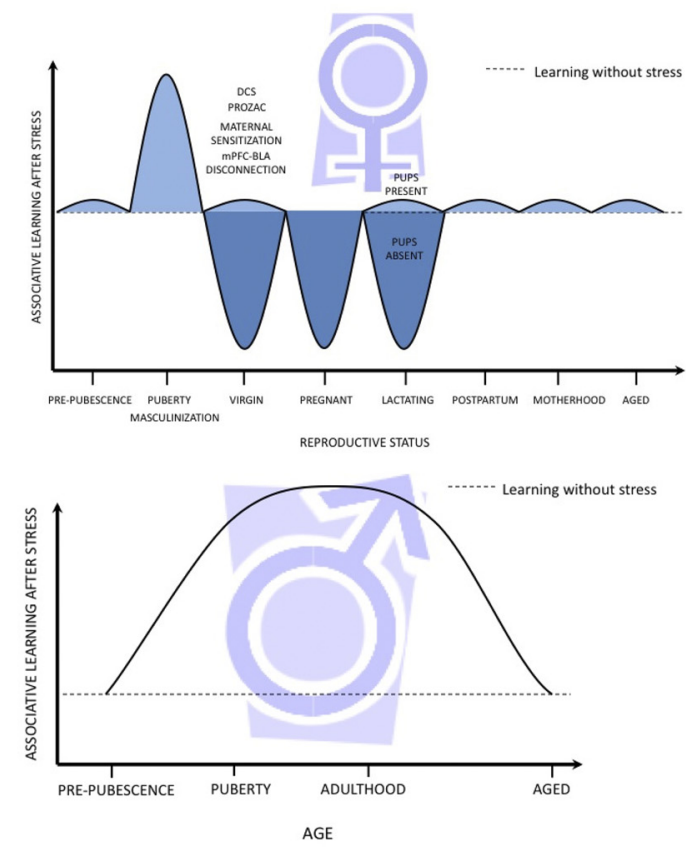

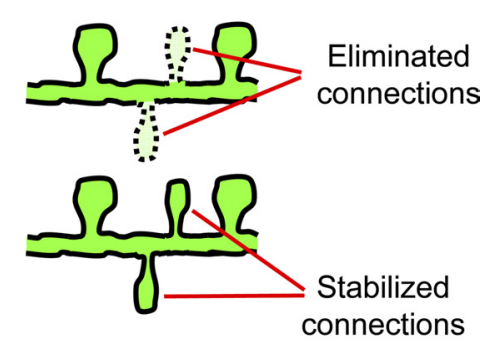

Novel connections

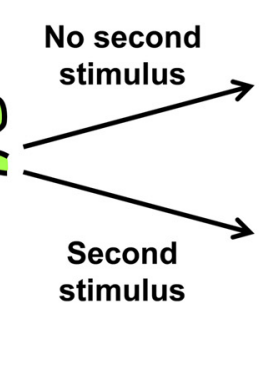

connections

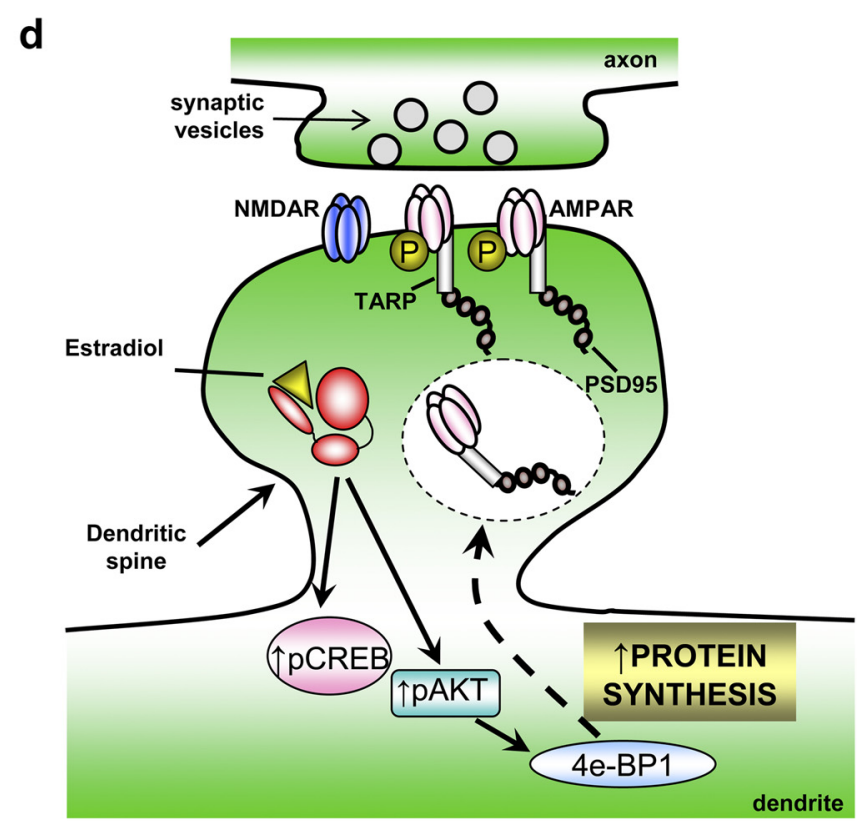

Figure 2. Examples of rapid estrogen-induced effects on neuronal circuitry. $\boldsymbol{a}$, Estradiol rapidly induces the formation of nascent synaptic connections in cortical neurons. Without a second stimulus, circuitry returns to control levels; addition of a second activity-dependent stimulus results in the stabilization and long-lasting increase in synaptic connectivity. $\boldsymbol{b}, \boldsymbol{c}$, The two diagrams illustrate persistent and opposite effects of acute stress on associative learning in females ( $\boldsymbol{b}$ ) versus males (c). Under unstressed conditions, females outperform males. However, after stress, females do not learn well, whereas males express more learned responses. The effects of stress on learning change numerous times across the female lifespan and can be ameliorated by various treatments and hormonal manipulations. In contrast, learning in males is less dynamic, with enhanced responding from puberty through middle age. $\boldsymbol{d}$, The proposed model for rapid translational mechanism underlying estrogen-mediated synaptic plasticity in hippocampal neurons. Estrogen alleviates downstream translational repression, such as controlled by eukaryotic initiation factor 4E-binding protein 1 (4E-BP1). This results in the upregulation of key synaptic modulators such as PSD-95 and GluA1, and may alter dendritic and synaptic structure as well as the facilitation of LTP.

In rat cortical neurons, estradiol has been shown to rapidly induce the formation of novel dendritic spines within $30 \mathrm{~min}$ (Srivastava et al., 2008). These novel protrusions contain a number of synaptic proteins, including PSD-95 and GluN1-containing NMDA receptors. Furthermore, they form contacts with presynaptic termini, demonstrating a transient increase in connectivity. In addition, activation of $\operatorname{ER} \beta$ in cortical neurons also increased spine density within $30 \mathrm{~min}$ (Srivastava et al., 2010). These novel protrusions also contained PSD-95 and make connections with presynaptic termini. Interestingly, estradiol-induced dendritic spines were only transient, and were preferentially eliminated by $60 \mathrm{~min}$, returning spine density to control levels by $60 \mathrm{~min}$, suggesting that estradiol is able to transiently increase the connectivity of cortical neurons (Srivastava et al., 2008) (Fig. 2a).

Recent studies have started to elucidate the signaling pathways important in the remodeling of dendritic spines (Tada and Sheng, 2006; Penzes et al., 2008; Yoshihara et al., 2009). The small GTPase family and their associated signaling cascades represent prime candidates for mediating estradiol's effects on dendritic spines, through the regulation of the actin cytoskeleton. Indeed, treatment with estradiol resulted in the activation of the small GTPase Rap, in a timeframe mimicking estradiol's effects on dendritic spines. Furthermore, acute treatment with estradiol resulted in the phosphorylation (activation) of extracellular signalregulated kinase (ERK) $1 / 2$ and an increase in synaptic clustering of the PDZ protein afadin (also known as AF-6) in the same timeframe, suggesting that these proteins may play a role in mediating estradiol's effects on dendritic spines. Interestingly, as described above, coupling of estrogen receptors with mGluRs can lead to the activation of MAP kinase-dependent pathways, suggesting that a potential pathway that can lead to the activation of ERK1/2 in cortical neurons. However, whether mGluRs or caveolin proteins are required for estradiol-mediated spine formation has yet to be determined. Importantly, blocking Rap, ERK1/2 or afadin function was sufficient to block estradiol-induced increases in dendritic spine density, thus demonstrating a role for these proteins in estradiol-mediated increase in cortical connectivity (Srivastava et al., 2008).

It is also interesting to note that structural plasticity is often accompanied by alterations in synaptic function induced by the 
trafficking of glutamate receptors to and/or from synapses (Segal, 2005). In cortical neurons, estradiol induced the bidirectional trafficking of GluA1-containing AMPA glutamate receptors; synaptic expression of GluA1 was reduced after 30 min of treatment with estradiol, but returned to control levels by $60 \mathrm{~min}$. Consistent with this trafficking, a transient decrease in AMPA receptormediated transmission was observed after $30 \mathrm{~min}$, but not after $60 \mathrm{~min}$, of treatment with estradiol.

A key question lies in understanding the relevance of these transient effects of estradiol on synapse structure and function and how they may relate to overall effects on neuronal circuitry. One possibility is that estradiol's transient effects may serve to prime neurons to respond to subsequent stimuli with greater efficacy, as has been suggested to occur following the generation of nascent connections (Kasai et al., 2010b). In support of this hypothesis, the coupling of estradiol treatment with a chemical long-term potentiation (cLTP) protocol, mimicking an activitydependent stimulus, resulted in a sustained increase in connectivity for up to $24 \mathrm{~h}$. Moreover, an increase in surface synaptic expression of AMPA receptors and an increase in AMPA receptor-mediated transmission were also observed. It is of note that the trafficking of AMPA receptors induced by estradiol most likely occurs via a nongenomic pathway that does not require gene transcription. However, it is currently not clear whether a translational mechanism such as that mediated by local protein synthesis (described below) is required for the increase in surface synaptic expression of AMPA receptors following the combined treatment of estradiol with a cLTP.

This cellular model, termed "two-step wiring plasticity," may offer a cellular mechanism underpinning the acute effects of estradiol on cortical circuitry by regulating synaptic connectivity and glutamate receptors (Srivastava et al., 2008) (Fig. 2a). Furthermore, it may offer insights into potential mechanisms underlying the beneficial effects of estradiol in a number of neuronal pathologies.

\section{Estrogen and the subsynaptic cytoskeleton: surprising partners in regulating excitatory transmission}

The acute effects of estradiol on LTP and memory encoding have important implications for arguments about why cognitive performance fluctuates with the estrous cycle and declines with age (Markowska, 1999). They are also suggestive of therapeutic applications, particularly in the light of evidence that highly selective agonists for ER $\beta$ enhance plasticity and memory in the absence of many of estradiol's peripheral actions (Liu et al., 2008). However, further progress in these areas will require information about how estradiol produces its rapid actions.

Recent progress in understanding the effects of rapid estrogen signaling in the hippocampus strongly suggests that estrogen's rapid facilitatory effect on synaptic physiology involves the subsynaptic cytoskeleton (Kramár et al., 2009). Importantly, control of the actin cytoskeleton is essential for the remodeling of dendritic spines, for the trafficking of glutamate receptors, and in the stabilization of long-term potentiation (Penzes et al., 2008; Srivastava et al., 2008; Yoshihara et al., 2009). As such, control of the subsynaptic cytoskeleton by estrogens may contribute significantly to estrogen-induced fine-tuning of neuronal circuitry. Latrunculin, a highly selective toxin that prevents the assembly of actin monomers into filaments, completely blocks estradioltriggered increases in fast glutamatergic transmission. Moreover, estradiol causes actin polymerization in dendritic spines in adult hippocampal slices (Kramár et al., 2009). A search for the actin signaling pathway responsible for these effects led to a sequence composed of the small GTPase RhoA, its effector ROCK, LIM kinase, and the actin-severing protein cofilin (Kramár et al.,
2009). It has been shown that estradiol activates RhoA and causes the phosphorylation of cofilin at hippocampal synapses; furthermore, highly selectively inhibitors of ROCK completely block estradiol's actions on synaptic responses without affecting baseline physiology (Kramár et al., 2009).

The RhoA/LIMK/Cofilin actin polymerization pathway has been implicated in LTP (Chen et al., 2007; Rex et al., 2009) and therefore provides a plausible route whereby estradiol could enhance EPSPs. It is also involved in the production of new spines in cultured neurons. The critical question thus arises as to whether the actin signaling pathway involved in estradiol-induced facilitation of EPSPs is also responsible for estradiol actions on spine proliferation. A first step in addressing this issue is to determine how estradiol engages the RhoA-polymerization cascade. One possibility, as suggested by others, is that estradiol may transactivate neighboring receptors that then engage GTPase signaling, leading to cytoskeletal reorganization. Synaptic adhesion receptors belonging to the $\beta 1$ integrin family are a potential candidate since they are concentrated in synapses and play an essential role in activity-induced actin polymerization and LTP. In support of this notion, recently obtained preliminary data suggest that estradiol activates $\beta 1$ integrins in adult hippocampal slices. Notably, $\beta 1$ activation was evident at the same early time point at which estradiol begins to increase the amplitude of synaptic responses. Additional pilot studies then showed that neutralizing antibodies against the $\beta 1$ integrin completely blocked the facilitation of estradiol-induced increases in EPSPs. Therefore, these findings lead to a working model in which ER $\beta$ transactivates classes of receptors that engage in RhoA signaling, actin filament assembly, and enhanced synaptic responses in hippocampal neurons.

\section{Males and females use different brain circuits to learn after stressful life experience}

The potential rapid effects of estrogen on learning and memory processes are many. Estrogens most certainly contribute to learned thoughts and behaviors associated with sexual activity and reproduction as well as those engaged during motherhood and menopause. However, rapid effects of estrogen are probably not limited to learning about reproduction, per se, and are likely to include general mechanisms related to learning itself. For example, learning processes can be modified by the presence of estrogen during a stressful life event.

Exposure to an acute stressful event suppresses learning in female rats, as assessed by an associative learning task known as the classically conditioned eyeblink response (Wood and Shors, 1998) (Fig. 2b). The detrimental effect of stress on learning is induced in a relatively short period of time $(10-30 \mathrm{~min})$ but has a long-lasting effect on cognition, persisting days after the stressor has ceased (Wood et al., 2001). These effects of stress on learning are mediated by the presence of estrogen, because they do not occur in females that are ovariectomized or in those that are stressed in the presence of the selective estrogen receptor modulator tamoxifen. The deficit in learning is also sensitive to naturally varying levels of estrogen (Shors et al., 1998). It is not evident before maturation of the estrous cycle. In other words, prepubescent and pubescent females learn well even after a stressor (Hodes and Shors, 2005). Once females begin to cycle, the suppressed learning emerges. It is especially evident in females that are stressed during diestrus and trained during proestrus when estrogen levels are elevated. Moreover, the suppression is not evident in females that are lactating or even in virgins that are simply caring for young (Leuner and Shors, 2006). Finally, we 


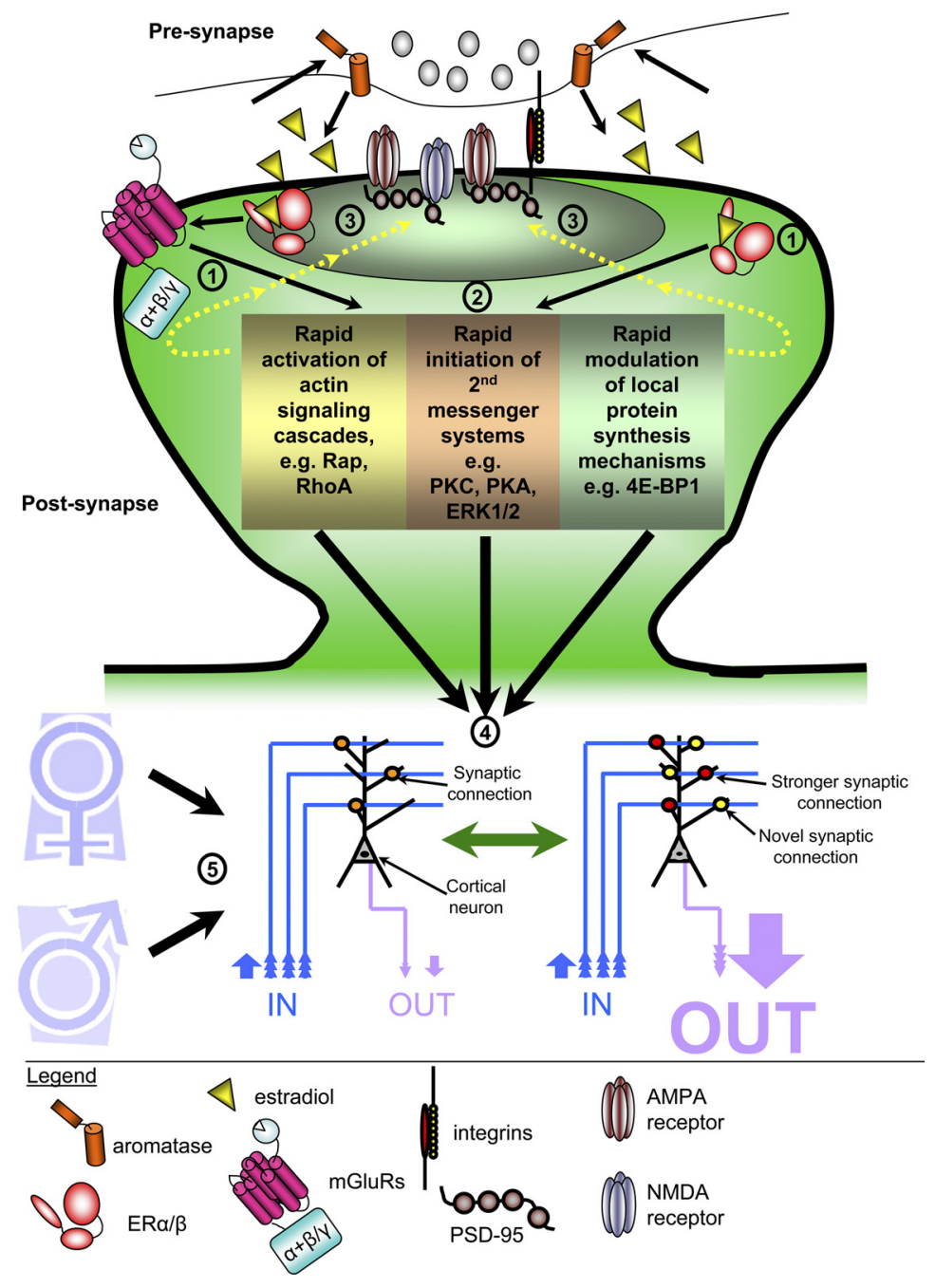

Figure 3. Schematic of rapid estrogen actions in neurons. 1, Activation of synaptically located $E R \alpha$ or $E R \beta$ can result in the transactivation of mGluRs. 2, Activation of ER/mGluR (or just ER) results in the activation of specific intracellular mechanisms, including activation of kinases, small GTPases, or local protein synthesis mechanisms. Importantly, neurons in different areas of the brain (i.e., cortex vs hippocampus) result in the activation of distinct mechanisms. 3, Rapid activation of intracellular cascades induces changes in synaptic protein localization and expression levels. 4, The cumulative effect of rapid estrogen signaling results in the modulation of synaptic connectivity and synaptic function, and thus the fine-tuning of neuronal circuitry. 5, Estrogen-mediated fine-tuning of specific neuronal circuitry for the encoding of specific cognitive behaviors is regulated by both sex and stressful events.

have recent evidence to suggest that learning in females with any offspring whatsoever is immune to the effects of stress on learning (Maeng and Shors, 2011). In summary, it is clear that estrogen not only has powerful consequences for processes of learning, but these effects are dynamic and impermanent.

Interestingly enough, males that are exposed to the same stressful event actually learn much better (Wood and Shors, 1998) (Fig. 2c). The enhanced learning is not observed if they are adrenalectomized (Wood et al., 2001). Castration is of no consequence regardless of when it occurs. That said, females that are masculinized at birth behave as males when they reach adulthood (Shors and Miesegaes, 2002). With these studies, one can conclude that these opposite effects of stress on learning are organized by the presence of sex hormones in utero and/or during early development.

The circuitry through which these sex differences occur is just now emerging. The hippocampus and the basolateral nucleus of the amygdala are necessary for both the enhanced learning in males after stress and the suppression of learning in females after stress (Bangasser and Shors, 2007; Waddell et al., 2008). However, other critical structures differ between the sexes. For example, the bed nucleus of the stria terminalis is necessary in males but not in females, unless they have been masculinized at birth (Bangasser and Shors, 2008). The medial prefrontal cortex is necessary for the suppressed learning in females after stress, but not the enhanced performance in males after stress (Maeng et al., 2010). Finally, recent data suggest that communication between the prefrontal cortex and amygdala is necessary for the suppressed learning in females after stress (Maeng et al., 2010).

Together, these studies indicate that females and males can use different brain regions to modify learning after an acute stressful experience. Because the brain regions are different, the circuits that are critically engaged must also be different (albeit, under these limited conditions). Thus, the mechanisms that are both necessary and sufficient for these particular sex differences in learning must be different as well. Using inactivation procedures, it is clear that at least some of the stress effects on learning discussed here occur during the stressful experience itself and therefore are induced within minutes or tens of minutes. That said, it is unclear whether they are as "rapid" as other estrogen-related mechanisms and may even depend on changes in gene expression. It is more likely a combination of mechanisms, both rapid and sustained, that accounts for the complex nature of stress/learning interactions. Furthermore, these mechanisms may have implications not only for how information is encoded in a sex-specific manner, but also for why sexual dimorphisms occur in the susceptibility, symptomatology, and course of a number of brain disorders that affect cognition.

\section{Estrogen effects on rapid protein synthesis through a} translation-dependent mechanism

The predominant model of rapid estrogen signaling occurs via a nongenomic mechanism, not involving gene transcription. However, recent data indicates that rapid effects of estrogen can involve local protein synthesis, which is a critical component of long-lasting hippocampal synaptic plasticity (Klann et al., 2004). Interestingly, ribosomes, translation factors, and mRNA are present not only in the neuronal soma, but also in dendrites and dendritic spines (Steward and Schuman, 2001). This indicates that local protein synthesis in the vicinity of the synapse could support long-lasting synaptic plasticity without engaging transcriptional processes in the neuronal soma. Estrogen can also regulate rapid protein synthesis, mainly through a translation-dependent mechanism. Estrogen has been shown to stimulate the rapid activation of specific signal transduction pathways, such as the activation of Akt (protein kinase B), a key signal transduction intermediate that initiates protein translation by alleviating the downstream translational repression of eukaryotic 
initiation factor 4E-binding protein 1 (4E-BP1) (Akama and McEwen, 2003). Specifically, estrogen rapidly (within $1 \mathrm{~h}$ ) increases the phosphorylation of Akt, as well as the phosphorylation of 4E-BP1, which suggests a mechanism leading to protein translation of dendrite-localized mRNA transcripts in the hippocampus in vivo.

Recently, ER $\beta$ activation by a selective agonist was shown to enhance LTP, increase dendritic branching, and produce changes in spine morphology. These changes are paralleled by upregulation of a number of key synaptic proteins, including the AMPAR subunit GluA1 and PSD-95. The relatively short timeframe (1-4 $\mathrm{h}$ after a single injection of the ER $\beta$ selective agonist) within which ER $\beta$ activation drives changes in synaptic protein levels (Liu et al., 2008) suggests a nongenomic mechanism of action. Consistent with the potential translation of dendritic proteins, estrogen and the ER $\beta$-selective agonist stimulate a rapid increase in PSD-95 and GluA1 new protein synthesis without altering PSD-95 and GluA1 mRNA levels. In the hippocampal slices, the rapid increases in synaptic protein levels correlate with estrogenand $\operatorname{ER} \beta$ ( $2 \mathrm{~h}$ incubation)-mediated enhancement of LTP, and these effects appear to be independent of gene transcription. This time course appears to be slightly longer than what has been described in rapid spine density changes and cytoskeletonmediated LTP, but these data clearly suggest that estradiol and $\mathrm{ER} \beta$, through activating translational machinery and triggering rapid protein synthesis, can regulate modulators of synaptic plasticity, in a timescale more rapid than that of classical actions of estrogens. Future studies will need to focus on whether this rapid translation is the key mechanism underlying estrogen- and ER $\beta$ mediated memory enhancement previously described (Liu et al., 2008).

\section{Summary}

In summary, new insights into the mechanisms underlying rapid estrogen signaling in the brain and the consequences these actions have on neuronal circuitry and behavior are rapidly emerging on multiple fronts. These include the subcellular localization of estrogen receptors and the mechanism(s) that allow for the coupling of these receptors with classic second messenger systems. This places the machinery required for initiating rapid estrogen signaling at synapses, thus allowing for the rapid modulation of synaptic properties (Fig. 3). At the cellular level, we are beginning to understand how the rapid initiation of signaling cascades can regulate actin cytoskeletal dynamics to regulate synapse structure and function. Moreover, the pairing of rapid estrogen signaling with activity-dependent stimuli can result in long-lasting changes in neuronal circuitry. Importantly, it is now emerging that the mechanisms used by estrogens are greatly influenced by cell type, as demonstrated by differences in the rapid effects of estrogen in cortical and hippocampal neurons and the preferential coupling of ERs to different mGluRs in distinct regions of the brain, and may ultimately lead to differential regulation of neuronal circuitry in each area. Furthermore, the effects of rapid estrogen signaling are not limited to changes in neuronal connectivity and synaptic transmission, but can influence the very nature of the circuitry is used for the acquisition of learned behaviors under stressful conditions in a sex-specific manner. Finally, the evidence that rapid estrogen signaling can lead to activation of molecular pathways that can regulate local synthesis pathways provides a novel direction for our understanding of rapid estrogen signaling within the brain and its ability to induce the fine-tuning of neuronal circuits (Fig. 3).

A number of CNS disorders, including Alzheimer's disease, schizophrenia and affective disorders, display aberrant synapse structure, function, and circuitry. Therefore, development of effective treatments for such disorders demands elucidation of the mechanisms controlling remodeling of synaptic networks. The rapid actions of estrogens on remodeling of neural circuitry highlight the importance of using suitable blood-brain barrierpenetrant agents with this mechanism of action for the effective treatment of neurodevelopmental, neurodegenerative, and psychiatric disorders. For example, targeting specific estrogen receptors, such as $\operatorname{ER} \beta$ receptors, without inducing feminizing side effects, may provide a novel therapeutic approach for the treatment of Alzheimer's disease, affective disorders, and schizophrenia. Moreover, in contrast to estradiol, such estrogen receptorbased agents could be used as a potential treatment approach in both males and female patients.

\section{References}

Adams MM, Shah RA, Janssen WG, Morrison JH (2001) Different modes of hippocampal plasticity in response to estrogen in young and aged female rats. Proc Natl Acad Sci U S A 98:8071-8076.

Adams MM, Fink SE, Shah RA, Janssen WG, Hayashi S, Milner TA, McEwen BS, Morrison JH (2002) Estrogen and aging affect the subcellular distribution of estrogen receptor-alpha in the hippocampus of female rats. J Neurosci 22:3608-3614.

Akama KT, McEwen BS (2003) Estrogen stimulates postsynaptic density-95 rapid protein synthesis via the Akt/protein kinase B pathway. J Neurosci 23:2333-2339.

Alvarez VA, Sabatini BL (2007) Anatomical and physiological plasticity of dendritic spines. Annu Rev Neurosci 30:79-97.

Balthazart J, Ball GF (2006) Is brain estradiol a hormone or a neurotransmitter? Trends Neurosci 29:241-249.

Bangasser DA, Shors TJ (2007) The hippocampus is necessary for enhancements and impairments of learning following stress. Nat Neurosci 10:1401-1403.

Bangasser DA, Shors TJ (2008) The bed nucleus of the stria terminalis modulates learning after stress in masculinized but not cycling females. J Neurosci 28:6383-6387.

Blaustein JD (2008) An estrogen by any other name. Endocrinology 149:2697-2698.

Boulware MI, Weick JP, Becklund BR, Kuo SP, Groth RD, Mermelstein PG (2005) Estradiol activates group I and II metabotropic glutamate receptor signaling, leading to opposing influences on cAMP response elementbinding protein. J Neurosci 25:5066-5078.

Boulware MI, Kordasiewicz H, Mermelstein PG (2007) Caveolin proteins are essential for distinct effects of membrane estrogen receptors in neurons. J Neurosci 27:9941-9950.

Boulware MI, Kent BA, Frick KM (2011) The impact of age-related ovarian hormone loss on cognitive and neural function. Curr Top Behav Neurosci. Advance online publication. doi: 10.1007/7854_2011_122.

Brinton RD (2009) Estrogen-induced plasticity from cells to circuits: predictions for cognitive function. Trends Pharmacol Sci 30:212-222.

Chaban VV, Li J, McDonald JS, Rapkin A, Micevych P (2007) Estradiol attenuates ATP-induced increase of $\left[\mathrm{Ca}^{2+}\right]_{i}$ through group II metabotropic glutamate receptors in rat DRG neurons. Soc Neurosci Abstr 33:519.7.

Chen LY, Rex CS, Casale MS, Gall CM, Lynch G (2007) Changes in synaptic morphology accompany actin signaling during LTP. J Neurosci 27:5363-5372.

Chklovskii DB, Mel BW, Svoboda K (2004) Cortical rewiring and information storage. Nature 431:782-788.

Cornil CA, Ball GF, Balthazart J (2006) Functional significance of the rapid regulation of brain estrogen action: where do the estrogens come from? Brain Res 1126:2-26.

DeBello WM (2008) Micro-rewiring as a substrate for learning. Trends Neurosci 31:577-584.

Dewing P, Boulware MI, Sinchak K, Christensen A, Mermelstein PG, Micevych P (2007) Membrane estrogen receptor- $\alpha$ interactions with metabotropic glutamate receptor la modulate female sexual receptivity in rats. J Neurosci 27:9294-9300.

Fiala JC, Spacek J, Harris KM (2002) Dendritic spine pathology: cause or 
consequence of neurological disorders? Brain Res Brain Res Rev 39:29-54.

Garcia-Segura LM (2008) Aromatase in the brain: not just for reproduction anymore. J Neuroendocrinol 20:705-712.

Grove-Strawser D, Boulware MI, Mermelstein PG (2010) Membrane estrogen receptors activate the metabotropic glutamate receptors mGluR5 and mGluR3 to bidirectionally regulate CREB phosphorylation in female rat striatal neurons. Neuroscience 170:1045-1055.

Herrick SP, Waters EM, Drake CT, McEwen BS, Milner TA (2006) Extranuclear estrogen receptor beta immunoreactivity is on doublecortincontaining cells in the adult and neonatal rat dentate gyrus. Brain Res 1121:46-58.

Hodes GE, Shors TJ (2005) Distinctive stress effects on learning during puberty. Horm Behav 48:163-171.

Holtmaat A, Svoboda K (2009) Experience-dependent structural synaptic plasticity in the mammalian brain. Nat Rev Neurosci 10:647-658.

Kasai H, Fukuda M, Watanabe S, Hayashi-Takagi A, Noguchi J (2010a) Structural dynamics of dendritic spines in memory and cognition. Trends Neurosci 33:121-129.

Kasai H, Hayama T, Ishikawa M, Watanabe S, Yagishita S, Noguchi J (2010b) Learning rules and persistence of dendritic spines. Eur J Neurosci 32:241-249.

Klann E, Antion MD, Banko JL, Hou L (2004) Synaptic plasticity and translation initiation. Learn Mem 11:365-372.

Kramár EA, Chen LY, Brandon NJ, Rex CS, Liu F, Gall CM, Lynch G (2009) Cytoskeletal changes underlie estrogen's acute effects on synaptic transmission and plasticity. J Neurosci 29:12982-12993.

Kuo J, Hamid N, Bondar G, Prossnitz ER, Micevych P (2010) Membrane estrogen receptors stimulate intracellular calcium release and progesterone synthesis in hypothalamic astrocytes. J Neurosci 30:12950-12957.

Leuner B, Shors TJ (2006) Learning during motherhood: a resistance to stress. Horm Behav 50:38-51.

Levin ER (2011) Minireview: extranuclear steroid receptors: roles in modulation of cell functions. Mol Endocrinol 25:377-384.

Liu F, Day M, Muñiz LC, Bitran D, Arias R, Revilla-Sanchez R, Grauer S, Zhang G, Kelley C, Pulito V, Sung A, Mervis RF, Navarra R, Hirst WD, Reinhart PH, Marquis KL, Moss SJ, Pangalos MN, Brandon NJ (2008) Activation of estrogen receptor-beta regulates hippocampal synaptic plasticity and improves memory. Nat Neurosci 11:334-343.

Luine VN (2008) Sex steroids and cognitive function. J Neuroendocrinol 20:866-872.

Maeng LY, Shors TJ (2011) Once a mother, always a mother: maternal experience protects females from the negative effects of stress on learning throughout their lifetime. Soc Neurosci Abstr 37:100.04.

Maeng LY, Waddell J, Shors TJ (2010) The prefrontal cortex communicates with the amygdala to impair learning after acute stress in females but not in males. J Neurosci 30:16188-16196.

Markowska AL (1999) Sex dimorphisms in the rate of age-related decline in spatial memory: relevance to alterations in the estrous cycle. J Neurosci 19:8122-8133.

McEwen BS, Alves SE (1999) Estrogen actions in the central nervous system. Endocr Rev 20:279-307.

Mermelstein PG, Becker JB, Surmeier DJ (1996) Estradiol reduces calcium currents in rat neostriatal neurons via a membrane receptor. J Neurosci 16:595-604.

Micevych PE, Mermelstein PG (2008) Membrane estrogen receptors acting through metabotropic glutamate receptors: an emerging mechanism of estrogen action in brain. Mol Neurobiol 38:66-77.

Micevych P, Bondar G, Kuo J (2010) Estrogen actions on neuroendocrine glia. Neuroendocrinology 91:211-222.

Milner TA, McEwen BS, Hayashi S, Li CJ, Reagan LP, Alves SE (2001) Ultrastructural evidence that hippocampal alpha estrogen receptors are located at extranuclear sites. J Comp Neurol 429:355-371.

Milner TA, Ayoola K, Drake CT, Herrick SP, Tabori NE, McEwen BS, Warrier S, Alves SE (2005) Ultrastructural localization of estrogen receptor beta immunoreactivity in the rat hippocampal formation. J Comp Neurol 491:81-95.

Mitterling KL, Spencer JL, Dziedzic N, Shenoy S, McCarthy K, Waters EM, McEwen BS, Milner TA (2010) Cellular and subcellular localization of estrogen and progestin receptor immunoreactivities in the mouse hippocampus. J Comp Neurol 518:2729-2743.

Paul SM, Purdy RH (1992) Neuroactive steroids. FASEB J 6:2311-2322.
Penzes P, Cahill ME, Jones KA, Srivastava DP (2008) Convergent CaMK and RacGEF signals control dendritic structure and function. Trends Cell Biol 18:405-413.

Penzes P, Woolfrey KM, Srivastava DP (2011a) Epac2-mediated dendritic spine remodeling: implications for disease. Mol Cell Neurosci 46:368-380.

Penzes P, Cahill ME, Jones KA, VanLeeuwen JE, Woolfrey KM (2011b) Dendritic spine pathology in neuropsychiatric disorders. Nat Neurosci 14:285-293.

Qiu J, Bosch MA, Tobias SC, Grandy DK, Scanlan TS, Ronnekleiv OK, Kelly MJ (2003) Rapid signaling of estrogen in hypothalamic neurons involves a novel G-protein-coupled estrogen receptor that activates protein kinase C. J Neurosci 23:9529-9540.

Remage-Healey L, Dong S, Maidment NT, Schlinger BA (2011) Presynaptic control of rapid estrogen fluctuations in the songbird auditory forebrain. J Neurosci 31:10034-10038.

Rex CS, Chen LY, Sharma A, Liu J, Babayan AH, Gall CM, Lynch G (2009) Different Rho GTPase-dependent signaling pathways initiate sequential steps in the consolidation of long-term potentiation. J Cell Biol 186:85-97.

Saldanha CJ, Remage-Healey L, Schlinger BA (2011) Synaptocrine signaling: steroid synthesis and action at the synapse. Endocr Rev 32:532-549.

Segal M (2005) Dendritic spines and long-term plasticity. Nat Rev Neurosci 6:277-284.

Shors TJ, Miesegaes G (2002) Testosterone in utero and at birth dictates how stressful experience will affect learning in adulthood. Proc Natl Acad Sci U S A 99:13955-13960.

Shors TJ, Lewczyk C, Pacynski M, Mathew PR, Pickett J (1998) Stages of estrous mediate the stress-induced impairment of associative learning in the female rat. Neuroreport 9:419-423.

Sierra A, Gottfried-Blackmore A, Milner TA, McEwen BS, Bulloch K (2008) Steroid hormone receptor expression and function in microglia. Glia 56:659-674.

Srivastava DP, Woolfrey KM, Jones KA, Shum CY, Lash LL, Swanson GT, Penzes P (2008) Rapid enhancement of two-step wiring plasticity by estrogen and NMDA receptor activity. Proc Natl Acad Sci U S A 105:14650-14655.

Srivastava DP, Woolfrey KM, Liu F, Brandon NJ, Penzes P (2010) Estrogen receptor $\beta$ activity modulates synaptic signaling and structure. J Neurosci 30:13454-13460.

Steward O, Schuman EM (2001) Protein synthesis at synaptic sites on dendrites. Annu Rev Neurosci 24:299-325.

Tada T, Sheng M (2006) Molecular mechanisms of dendritic spine morphogenesis. Curr Opin Neurobiol 16:95-101.

Towart LA, Alves SE, Znamensky V, Hayashi S, McEwen BS, Milner TA (2003) Subcellular relationships between cholinergic terminals and estrogen receptor-alpha in the dorsal hippocampus. J Comp Neurol 463:390-401.

van Spronsen M, Hoogenraad CC (2010) Synapse pathology in psychiatric and neurologic disease. Curr Neurol Neurosci Rep 10:207-214.

Waddell J, Bangasser DA, Shors TJ (2008) The basolateral nucleus of the amygdala is necessary to induce the opposing effects of stressful experience on learning in males and females. J Neurosci 28:5290-5294.

Waters EM, Yildirim M, Janssen WG, Lou WY, McEwen BS, Morrison JH, Milner TA (2011) Estrogen and aging affect the synaptic distribution of estrogen receptor beta-immunoreactivity in the CA1 region of female rat hippocampus. Brain Res 1379:86-97.

Wood GE, Shors TJ (1998) Stress facilitates classical conditioning in males, but impairs classical conditioning in females through activational effects of ovarian hormones. Proc Natl Acad Sci U S A 95:4066-4071.

Wood GE, Beylin AV, Shors TJ (2001) The contribution of adrenal and reproductive hormones to the opposing effects of stress on trace conditioning in males versus females. Behav Neurosci 115:175-187.

Woolley CS (2007) Acute effects of estrogen on neuronal physiology. Annu Rev Pharmacol Toxicol 47:657-680.

Wright CL, McCarthy MM (2009) Prostaglandin E2-induced masculinization of brain and behavior requires protein kinase A, AMPA/kainate, and metabotropic glutamate receptor signaling. J Neurosci 29:13274-13282.

Yang SH, Liu R, Perez EJ, Wen Y, Stevens SM Jr, Valencia T, BrunZinkernagel AM, Prokai L, Will Y, Dykens J, Koulen P, Simpkins JW (2004) Mitochondrial localization of estrogen receptor beta. Proc Natl Acad Sci U S A 101:4130-4135.

Yoshihara Y, De Roo M, Muller D (2009) Dendritic spine formation and stabilization. Curr Opin Neurobiol 19:146-153. 